\title{
Geodetic Constraints on the 2014 M 6.0 South Napa Earthquake
}

\section{by W. D. Barnhart, J. R. Murray, S.-H. Yun, J. L. Svarc, S. V. Samsonov, E. J. Fielding, B. A. Brooks, and P. Milillo}

Online Material: Figures showing InSAR and GPS observations, model residuals, slip distributions, predicted Coulomb stress changes, and time lines for model releases; tables of GPS displacements and fault geometry and orientation.

\section{INTRODUCTION}

On 24 August 2014, the M 6.0 South Napa earthquake shook much of the San Francisco Bay area, leading to significant damage in the Napa Valley. The earthquake occurred in the vicinity of the West Napa fault $\left(122.313^{\circ} \mathrm{W}, 38.22^{\circ} \mathrm{N}, 11.3 \mathrm{~km}\right)$, a mapped structure located between the Rodger's Creek and Green Valley faults, with nearly pure right-lateral strike-slip motion (strike $157^{\circ}$, dip $77^{\circ}$, rake $-169^{\circ}$; http://comcat.cr.usgs.gov/ earthquakes/eventpage/nc72282711\#summary, last accessed December 2014) (Fig. 1). The West Napa fault previously experienced an $\mathbf{M} 5$ strike-slip event in 2000 but otherwise exhibited no previous definitive evidence of historic earthquake rupture (Rodgers et al., 2008; Wesling and Hanson, 2008). Evans et al. (2012) found slip rates of $\sim 9.5 \mathrm{~mm} / \mathrm{yr}$ along the West Napa fault, with most slip rate models for the Bay area placing higher slip rates and greater earthquake potential on the Rodger's Creek and Green Valley faults, respectively (e.g., Savage et al., 1999; d'Alessio et al., 2005; Funning et al., 2007).

High-quality geodetic observations from both continuous and campaign Global Positioning System (GPS) networks in the Bay area, as well as Interferometric Synthetic Aperture Radar (InSAR), were collected in the days immediately following the earthquake (Fig. 2; (E) Fig. S1, available in the electronic supplement to this article). These observations recorded surface displacements generated by the earthquake, including both the coseismic surface displacement field and early postseismic deformation. In this study, we analyze these geodetic observations to map the fault location and static slip distribution (SD) of the South Napa earthquake and to assess associated static stress changes on neighboring faults. The location of the earthquake inferred from geodetic observations coincides with both mapped and unmapped sections of the West Napa fault, in agreement with our own and other's field observations of surface rupture (http://www.geerassociation.org/GEER_Post\%20EQ\%20Reports/ SouthNapa_2014/index.html; last accessed December 2014). The earthquake propagated northward from the epicenter with the majority of slip immediately adjacent to the city of Napa. Static stress change calculations show increased Coulomb stress on both the northern and southern continuations of the West Napa fault and through a releasing bend of the adjacent Rodgers Creek fault.

In addition to exploring the source properties of the Napa earthquake, this study details the methods used for U.S. Geological Survey National Earthquake Information Center (USGSNEIC) geodetic-based finite-fault inversions and to highlight the importance of rapidly updated geodetic observations, both in situ and remotely sensed, for event source characterization and response. Finite-fault SDs derived from teleseismic observations are an integral response product of the NEIC, providing critical spatial information for other products such as ShakeMap, ShakeCast, and Prompt Assessment of Global Earthquakes for Response (PAGER). Where available, geodetic observations complement these finite source models, providing additional constraint on slip location and complexity and expanding the characterized magnitude range of events (Figs. 2, 3). Events like the South Napa earthquake demonstrate the utility of geodetic observations in constraining slip complexity and resulting stress changes from small to moderate magnitude earthquakes. As a part of the response to the South Napa earthquake, these geodetic data sets were progressively incorporated into NEIC response products and made available to the public. The first GPS-based source model was released within 36 hours of the earthquake and then progressively revised as additional GPS displacements and InSAR observations became available (Fig. 3).

\section{OBSERVATIONS}

To constrain the spatial slip characteristics of the South Napa earthquake, we jointly inverted continuous and campaign GPS and InSAR observations from the Agenzia Spaziale Italiana (ASI) COSMO-SkyMed (CSK) X-band and Canadian Space Agency RADARSAT-2 (RS2) C-band satellites (Figs. 2 and (E) S1). We processed continuous and campaign GPS data using the GIPSY-OASIS II software developed by National Aeronautics and Space Administration's Jet Propulsion Laboratory (JPL). This software implements a precise point positioning approach (Zumberge et al., 1997) and single-station ambiguity 


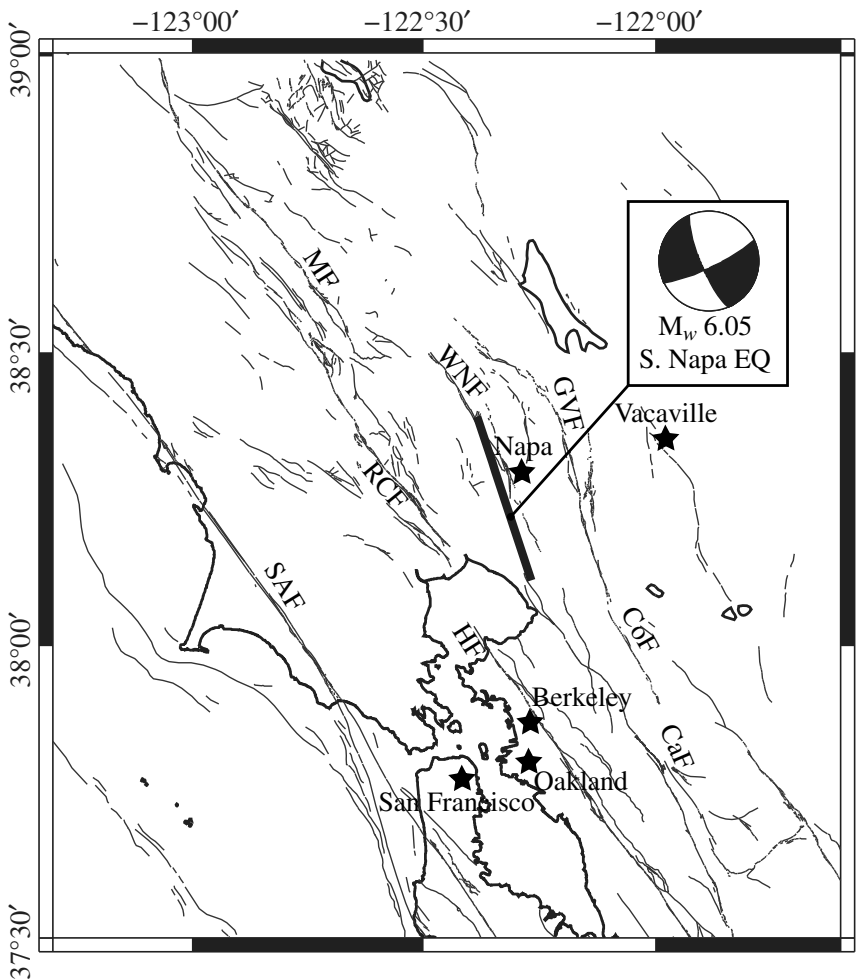

- Figure 1. Location and tectonic context of the South Napa earthquake, showing the U.S. Geological Survey (USGS) National Earthquake Information Center $W$-phase moment tensor and event epicenter. The bolded black line indicates the surface trace of fault geometeries used in this study to model the South Napa earthquake (see Fig. 2), whereas light gray lines are mapped Quaternary fault (USGS Quaternary fault database). The faults are abbreviated as follows: SAF, San Andreas fault; RCF, Rodgers Creek fault; WNF, West Napa fault; GVF, Green Valley fault; CoF, Concord fault; CaF, Calaveras fault; HF, Hayward fault; and MF, Maacama fault. Local cities are shown with black stars.

resolution (Bertiger et al., 2010), and we utilized Rapid orbit and clock files as well as wide lane and phase bias files generated by JPL. Final orbit and clock files would allow for more precise displacement estimates; however, these files are not available until up to 14 days after observation and would not be available in an operational capacity for immediate earthquake response and characterization. We reduced common mode scatter (Wdowinski et al., 1997; Dong et al., 2006) in the time series by defining a spatial filter using the velocities of a subset of long-running and stable continuous GPS sites (CMBB, DIAB, FARB, LNC1, MUSB, P314, SAOB, SODB, SUTB, and TIBB). The dayspecific filter was obtained by calculating the translation required to align those sites' daily positions with those predicted from their long-term trends. This filter was then applied to all stations in the network on each day.

To estimate coseismic displacements (ㅌ) Table S1), we applied the time-series analysis methodology of Langbein (2004) to each station component (east and north) time series from 1 January 2000 to 27 August 2014. This analysis approach, which accounts for temporally correlated noise, provides estimated uncertainties for the calculated displacements that are more realistic than would be obtained through standard weighted least-squares fitting. Murray et al. (2014) provide a detailed description of the processing and time-series analysis approach used here.

Field mapping of the surface rupture and inspection of continuous GPS time series suggested postseismic displacement began immediately after the earthquake. Because we use daily position estimates and the variable amount of time that elapsed between the earthquake and initial reoccupation of each campaign GPS site, the estimated offsets used in the modeling for each GPS site will include surface displacements from both the coseismic rupture and some early postseismic motion.

In addition to the GPS displacements, we use three interferograms: a descending CSK interferogram (26 July 2014-27 August 2014), an ascending CSK interferogram (19 June 2014-03 September 2014), and a descending RS2 interferogram (31 July 2014-17 September 2014), which include 3, 10, and 24 days of potential postseismic deformation, respectively (ㅌ) Fig. S1). The CSK interferograms were processed using the InSAR Scientific Computing Environment (ISCE) interferometric processing system (Zebker et al., 2010) by the Advanced Rapid Imaging and Analysis (ARIA) team at JPL-Caltech, in collaboration with the ASI and University of Basilicata. The interferogram was unwrapped using SNAPHU (Chen and Zebker, 2001) and masked using a signal coherence threshold. Phase unwrapping errors were manually fixed where possible and deleted from the interferograms if the correct phase ambiguity could not be discerned. The RS2 interferogram was processed by Natural Resources Canada (NRCAN) with the GAMMA processing system (Wegmuller and Werner, 1997) and unwrapped using the branch-cut region growing algorithm (Goldstein et al., 1988). The topographic phase was removed from both interferograms with the Shuttle Radar Topography Mission digital elevation model (Farr et al., 2007). Each interferogram was then downsampled to a computationally feasible $\left(\sim 10^{4}\right)$ number of observations, and the noise covariance structure was estimated for the resulting data set (Lohman and Simons, 2005; Lohman and Barnhart, 2010). Downsampled interferograms and resulting fits are shown in (E) Figure S1.

\section{FINITE-FAULT INVERSION}

Here, we describe our procedure for deriving a source model for the South Napa earthquake, which is followed for other events analyzed by the NEIC (Barnhart, Hayes, Briggs, et al., 2014; Barnhart, Hayes, Samsonov, et al., 2014; Hayes et al., 2014). Although field observations of fault rupture are available to more precisely constrain fault location, we explicitly do not use these to provide a synopsis of NEIC operations for global events where such observations would not be available, rapidly or otherwise. We instead compare our source model with field observations to demonstrate the ability of highquality geodetic observations to robustly constrain source characteristics that are consistent with field observations. 
(a)

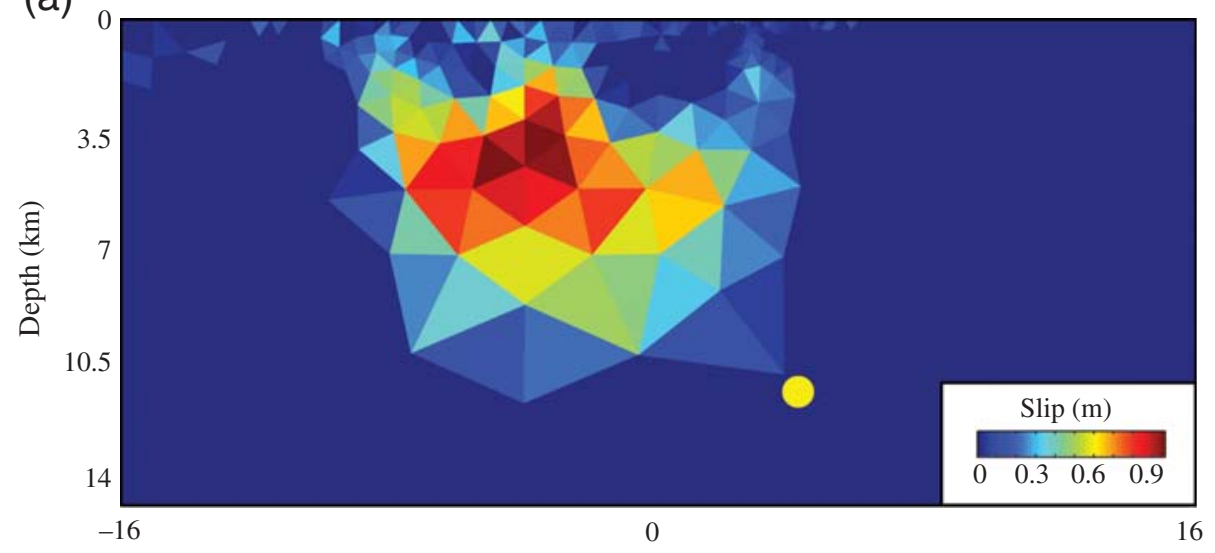

Distance Along Strike (km)

(c)

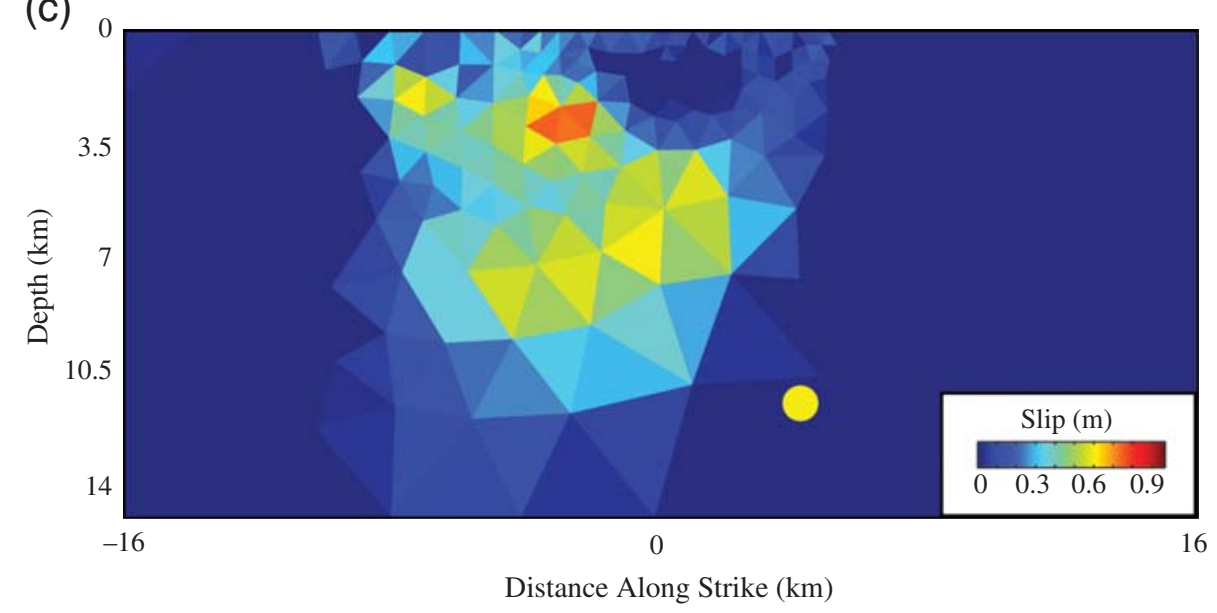

(b)

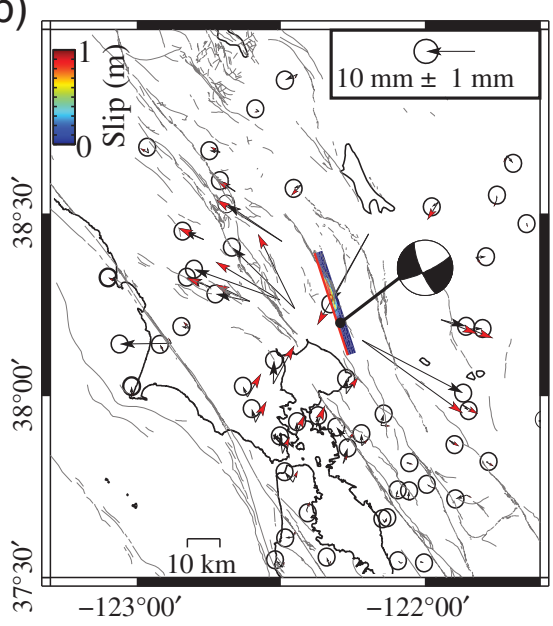

(d)

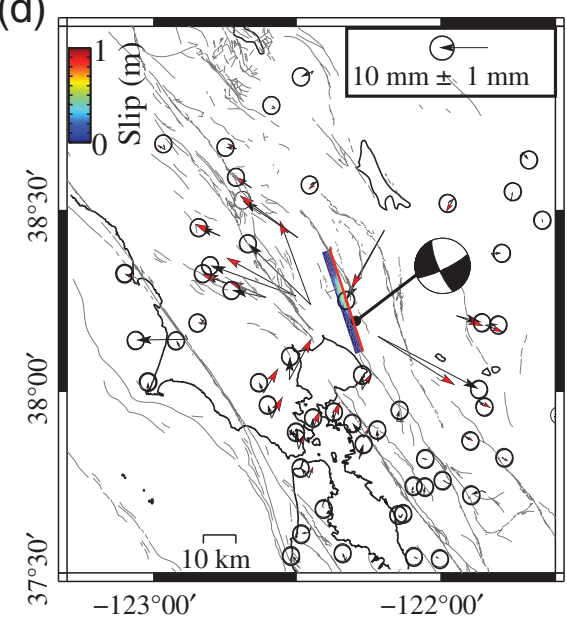

A Figure 2. Median-value finite slip distributions (SDs) derived from Monte Carlo analysis. (a, b) Plan and map view of the east-dipping focal plane (strike $341^{\circ}$, dip $80^{\circ}$ ) with observed (black) and modeled (red) continuous Global Positioning System (GPS) displacements. (c, d) Same views of the west-dipping focal plane (strike $161^{\circ}$, dip $76^{\circ}$ ) with observed (black) and modeled (red) continuous GPS displacements. The yellow dots in (a) and (c) denote the USGS hypocenter. Moment tensors in (b) and (d) are the USGS W-phase solution. Local faults, including the West Napa fault, are plotted in light gray (USGS Quaternary fault database), and a thick red line demarcates the surface trace of the fault geometries shown in (a) and (c). Resampled interferograms, campaign GPS displacements, and fits to each are shown in (E) Figure S1.

To derive a source model and corresponding uncertainties for the South Napa earthquake, we begin by jointly inverting the GPS and downsampled InSAR observations for the location (longitude, latitude, and depth), orientation (strike, dip, and rake), and dimensions (along-strike length and down-dip width) of a single-fault patch with homogeneous slip embedded in a homogeneous elastic half-space using the neighborhood algorithm (Okada, 1992; Sambridge, 1999). We do not use seismic event location information (i.e., hypocenter) to precondition the inversion as earthquakes in other locations globally may be mislocated by tens of kilometers (e.g., Elliott et al., 2010; Devlin et al., 2012; Barnhart et al., 2013). Event moment tensors variably indicate the ruptured fault dipped steeply to the west or east (http://earthquake.usgs.gov/earthquakes/ eventpage/nc72282711\#scientific_moment-tensor; last accessed December 2014), so we allow the neighborhood algorithm to sample both dip domains, searching over a broad range of strike, dip, and rake within each region of model space. Inversions for slip on a single-fault patch nominally prefer an east-dipping plane, but differences in misfits are small; thus, we present results for both a west- and an east-dipping structure (ㅌ) Table S2). After deriving a preferred fault geometry (strike $341^{\circ} / 161^{\circ}$, dip $80^{\circ} / 76^{\circ}$, values indicate orientation or east and west dipping planes, respectively) and location, we fix the fault plane in space and extend the fault both along strike and down dip. We then invert the GPS and InSAR observations for distributed slip using an iterative method in which the fault is discretized with variably sized triangles that reflect the model resolution afforded by the surface observations (Barnhart and Lohman, 2010) (Figs. 2, (E) S2). We choose the best SD for both the east- and west-dipping fault geometries using the ${ }_{j} R_{i}$ criterion (Barnhart and Lohman, 2010), and we impose length 

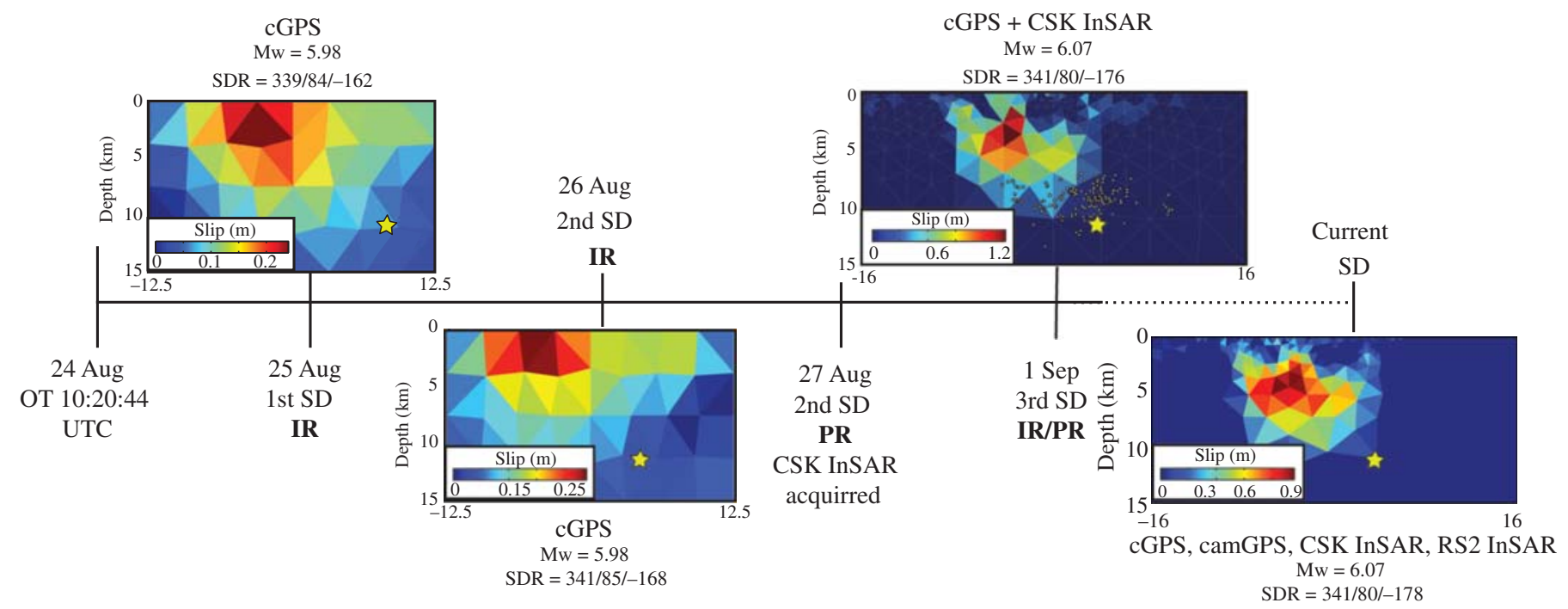

- Figure 3. Time line of SD releases, both internal releases (IR) within the USGS through the Geodetic Centroid Bulletin (gCent Bulletin, (E) Fig. S5) and public releases (PR) through the South Napa event page. Each iteration includes GPS displacements with additional oneday solutions provided by the USGS Earthquake Science Center, and the third and final posted SD (1 September 2014) include the first available CSK interferogram only. The differences between the final distributed slip model and current slip models that include additional InSAR constraints are small, demonstrating the timeline and data needs necessary for accurate slip characterization. The yellow stars indicate the location of the USGS hypocenter; the white dots in the 1 September SD indicate preliminary aftershock locations released by the USGS; cGPS refers to continuous GPS; and camGPS referes to campaign GPS. IR occurred through the $g$ Cent Bulletin, PR occurred on the USGS event page. SDR indicates strike/dip/rake of the fault-plane/slip distribution.

scale independent minimum-moment regularization and constant slip direction (rake) based on the results of the neighborhood algorithm. We use minimum-moment regularization so that extending the dimensions of the source fault does not bias our SD.

We additionally estimate uncertainties on the derived SDs that are then propagated through our Coulomb stress change (CSC) analysis (ㅌ) Fig. S2). We implement a Monte Carlo error propagation approach (Barnhart et al., 2011) wherein we generate 1000 synthetic noisy data sets by adding Gaussian distributed random noise to the predicted displacements from our best SDs. All observations and corresponding Green's functions are preweighted by the Cholesky inverse of the noise covariance matrix (Barnhart and Lohman, 2010); thus, the spatially correlated nature of the InSAR noise and the nonspatially correlated nature of the GPS noise are both accounted for when Gaussian noise is added. We then invert the population of synthetic data sets for slip onto the same fault discretization derived previously with identical regularization. This approach quantifies uncertainties induced by the imposed regularization and noise in the observations that propagate into the SD; it does not account for other sources of uncertainty, such as unmodeled fault geometry complexity or real Earth rigidity structure. As the inversion is inherently nonlinear due to the inclusion of positivity constraints, we present the median and the 16th and 84th (1- $\sigma$ uncertainties) percentiles of the population of slip models (Figs. 2, (E) S2).

Finally, we explore the stressing effects of the South Napa earthquake on nearby faults in the Bay area, including the Rodger's Creek-Hayward and Green Valley-Concord fault systems, and the San Andreas fault (Figs. 4, () S3). We use the population of slip models derived previously and the same uniform elastic half-space to calculate the CSCs on these faults, using the fault geometries of the UCERF 3 model (Field et al., 2014). CSC has been shown to be a potential mechanism by which faults within the vicinity of an earthquake are either relaxed or brought closer to failure (e.g., Harris, 1998; Stein, 1999; Kilb et al., 2000; Freed, 2005). Quantifying the stress changes on nearby faults may then assist in constraining the locations of aftershocks or triggered earthquakes immediately following an event (Jordan et al., 2014). The CSCs that we show are resolved into the slip direction of each fault assuming pure right-lateral slip. For both the east- and west-dipping planes, we calculate the CSCs on local receiver faults assuming static coefficients of friction of 0.4 (Fig. 4) and 0.0 (frictionless, (E) Fig. S3).

With respect to the timeline of event response products (Fig. 3), SDs were progressively released both internally to USGS personnel and to the public through the USGS event page. Fault slip distributions were updated and revised as improved and new geodetic observations became available. Coseismic displacements from continuous GPS stations in the Bay area were available and modeled one day after the earthquake on 25 August 2014. This SD, along with the first finite source model from local seismic recordings, was released internally to the USGS the same day. Displacements from these stations were updated again on 26 and 27 August using one-day orbits that progressively improved uncertainties but included further postseismic displacements. The first publicly released SDs included observations from continuous GPS only (Fig. 3), and it did not 
(a)

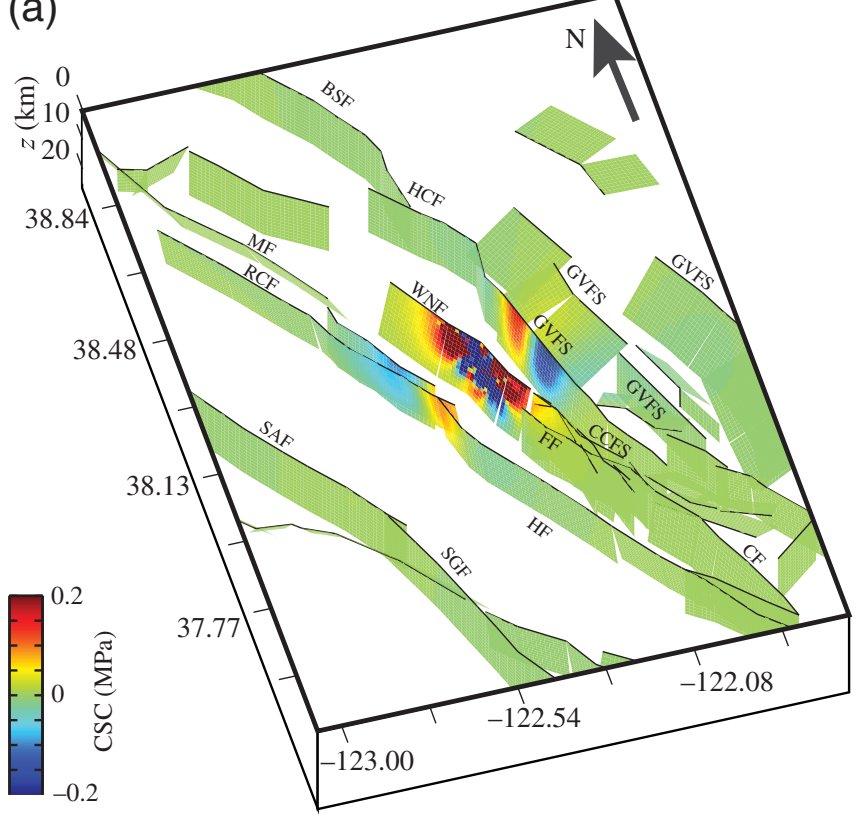

(c)

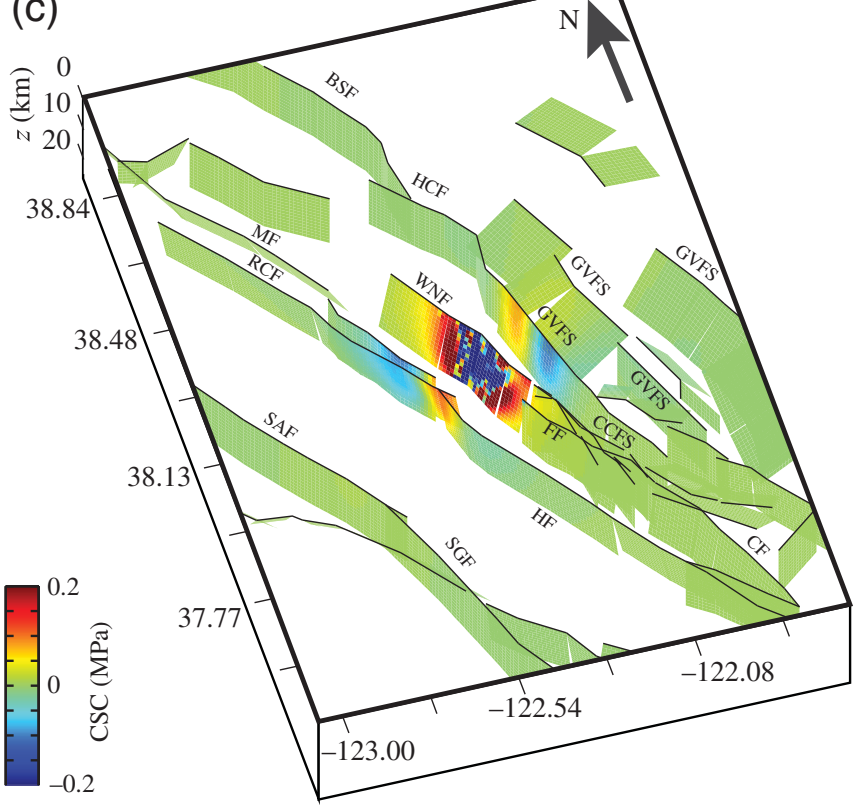

(b)

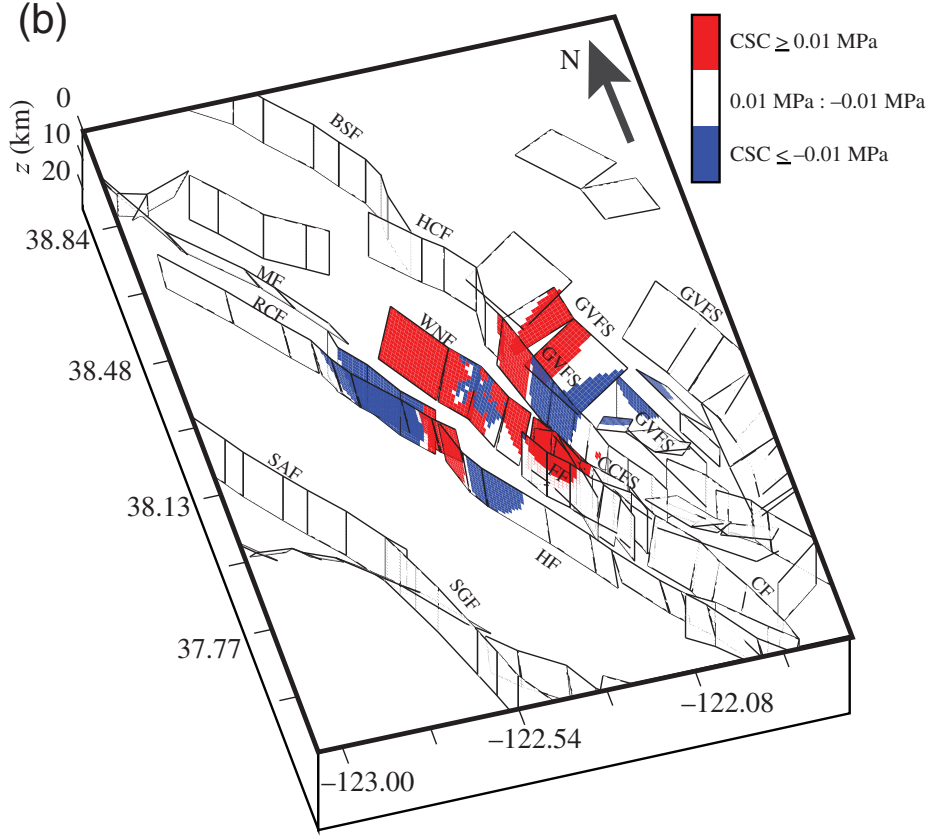

(d)

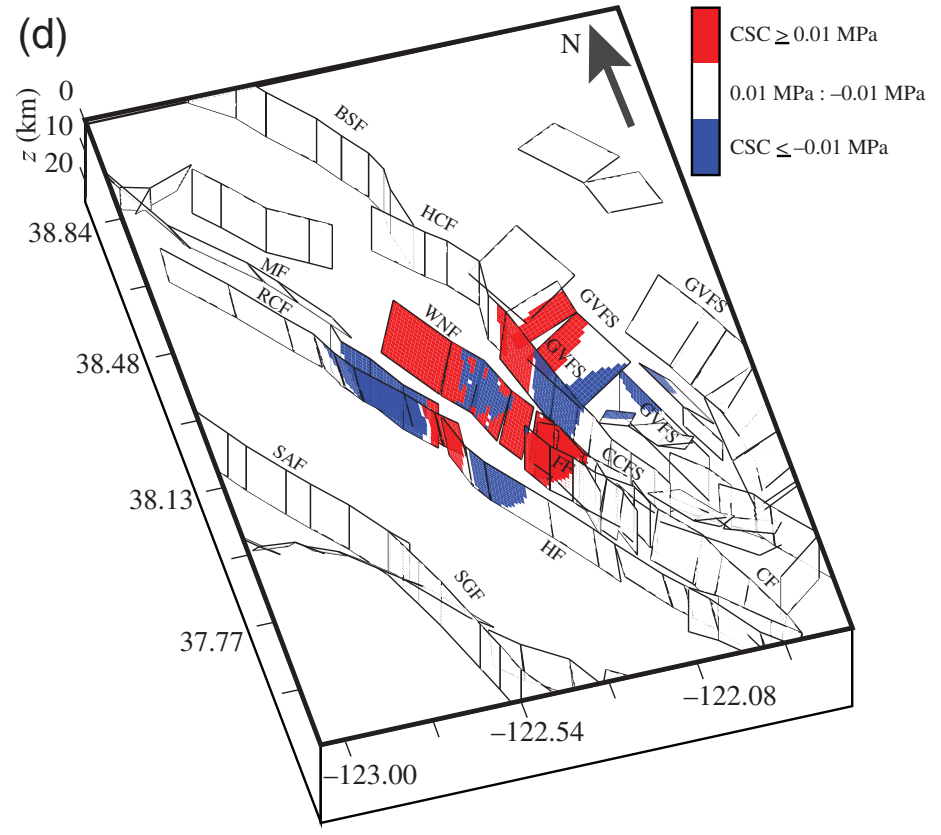

A Figure 4. Coulomb stress change (CSC) calculations (friction is 0.4 ) for the (a, b) east-dipping and (c, d) west-dipping models. (a) and (c) show the CSC resolved in the slip direction of fault geometries (Field et al., 2014). Black traces indicate the tops of faults. (b) and (d) show locations on faults where stress changes exceed $\pm 0.01 \mathrm{MPa}$. Red and blue regions indicate where the fault stress increase and decrease, respectively, exceeds this threshold. White regions indicate stress changes of 0.01 and $-0.01 \mathrm{MPa}$. Abbreviations of major faults from the UCERF fault database are shown: SAF, San Andreas fault; SGF, San Gregorio fault; RCF, Rodgers Creek fault; HF, Hayward fault; WNF, West Napa fault; MF, Maacama fault; HCF, Hunting Creek fault; BSF, Bartlett Springs fault; GVFS, Green Valley fault system; CCFS, Conta Costa fault system; FF, Franklin fault; and CF, Calaveras fault. (Not all faults shown in the image are named here.)

incorporate the variable fault patch discretization algorithm. The first CSK interferogram was acquired on 27 August and made available on 28 August. The final SD posted to the USGS event page was posted on 1 September and included only the continuous GPS observations through 27 August and the descending CSK interferogram (Fig. 3). The final SDs presented in this article
(Figs. 2, 3) include all of the observations described in the previous section. Internal USGS releases were made through the Geodetic Centroid Bulletin (ㅌ) Fig. S5), a document that includes such relevant information on modeling of the earthquake as data types used, inverted fault geometry and location, SD, and comparisons with other SDs and centroid moment tensors. 


\section{RESULTS}

Our scientific analysis focuses on results of SDs produced using the full data sets described previously (continuous and campaign GPS, CSK, and RS2 interferograms); however, many of these observations were not available on time scales appropriate for event response (Fig. 3). Nonetheless, the first SD (1 September) that included both continuous GPS and the descending CSK interferogram is remarkably similar to the final (current) SD (Figs. 2, 3). To the degree of complexity that we undertook fault slip modeling, these results demonstrate the earthquake slip characteristics were well resolved by only a small subset of the data that would later become available. For a shallow, continental earthquake like this, a single interferogram may be adequate to accurately constrain fault slip characteristics for use in earthquake response products.

Our final fault slip inversions, fits to observations, and inferred CSCs are shown in Figures 2, () S1-S3, and 4, respectively. Both end-member SDs exhibit similar spatial patterns with slip primarily occurring between the surface and $10.5 \mathrm{~km}$ depth, peak slip located from 2.5 to $7 \mathrm{~km}$ depth, and the majority of slip imaged north of the event hypocenter. The relative locations of the hypocenter and slip centroid indicate the earthquake propagated up-dip and to the north, with the greatest slip occurring near the city of Napa. The USGS hypocenter is located within $500 \mathrm{~m}$ of the inverted fault-plane geometry. Except for an $\sim 1 \mathrm{~km}$ section, the traces of the geodetically-defined single fault-plane geometries do not overlap with the major strands of the previously mapped West Napa fault (Figs. 1, 2, (E) S4), indicating the South Napa earthquake, in part, ruptured previously unidentified portions of the West Napa fault. Furthermore, maximum surface slip values of $25-35 \mathrm{~cm}$ mapped by our inversion (Figs. 2, (E) S2) agree well in magnitude and location with our own and other's observations of co and postseismic slip measured in the field (http://www.geerassociation.org/GEER_Post\% 20EQ\%20Reports/SouthNapa_2014/index.html; last accessed December 2014). The estimated moment magnitude of each SD (east dipping is M $6.07 \pm 0.04$; west dipping is $6.03 \pm 0.05)$ is in agreement with the USGS-reported event magnitude $\left(M_{\mathrm{w}} 6.05\right)$.

The fits of our SDs to InSAR and GPS observations vary significantly in quality (Figs. 2, (E) S1). In general, the SDs best fit the observations with the shortest postseismic interval (descending CSK interferogram and continuous GPS observations) (Figs. 2, (E) S1). Conversely, predicted displacements systematically underpredict observations that include longer postseismic intervals (ㅌ) Fig. S1). We theorize the variable misfits arise from three sources: variations in observation quality and spatial coverage, variations in postseismic interval, and unmodeled faulting complexity. First, observations with the shortest postseismic intervals are coincidentally the highest quality observations in terms of lowest uncertainties, greatest spatial resolution, and least decorrelation in the interferogram. The campaign GPS observations have greater uncertainties than the continuous displacements, and the ascending CSK interferogram is highly decorrelated near the fault, largely due to its three-month time span. Likewise, the RS2 interferogram only spans a portion of the surface displacement field and includes a long postseismic interval.

As our inversion procedure weights observations according to both their noise covariance and considers the variable resolution of the data set, it would be expected that the less noisy displacements with greater spatial resolution (continuous GPS, descending CSK interferogram) would dominate the inversion. Second, significant near-surface afterslip was observed in the field following the earthquake (as much as $20 \mathrm{~cm}$ in some places in the 24 hours following the main shock), with deeper afterslip also likely (Brooks et al., 2014). Deep and shallow afterslip is further evidenced by the increase in continuous GPS displacements in the days immediately following the earthquake. Accordingly, geodetic observations with longer postseismic intervals likely include greater magnitudes of postseismic deformation than shorter time-interval observations. Some of this later postseismic deformation may not be mapped into our fault slip inversions, given that we systematically underfit observations with longer postseismic intervals. Our shortest postseismic interferogram interval is three days; thus, our SDs likely include a component of postseismic afterslip. But inspection of data misfits indicates we systematically under-fit observations with longer postseismic intervals, suggesting our models miss some afterslip that continues beyond this time frame. Inversion tests for slip on a single patch that only include observations with long postseismic intervals (RS2 and ascending CSK interferograms, campaign GPS) fit the included observations better with a similar fault geometry and location as before but have a resulting magnitude of $\sim \mathbf{M}$ 6.14-6.2, suggesting the presence of significant postseismic deformation. Last, misfits may arise from unmodeled fault complexity or variations in slip direction (though variable rake tests do not change misfits substantially) and shallow basin-induced deformation that does not necessarily reflect the coseismic rupture.

The static CSCs resulting from our SDs are shown in Figures 4 and (E) S3. As expected from the similarity between the SDs on alternating dip planes, the inferred stress changes are not highly sensitive to the chosen rupture geometry. The geodetic data, especially InSAR, constrain the major fault slip to the same location for both fault geometries. Conservatively, significant stress changes (>0.01 MPa or $<-0.01 \mathrm{MPa}$, one order of magnitude below the critical threshold postulated by Kilb et al., 2000) are restricted to faults in the vicinity of the mapped rupture and alternate in sign along the length of single faults. Both the northern and southern extensions of the West Napa fault are positively stressed, indicating increased earthquake potential. Likewise, portions of the Green Valley fault, the Contra Costa fault system, Franklin fault, and a releasing bend in the Rodgers Creek fault are positively stressed. However, in each case, regions of significant stress decrease bound regions of positive stress change. In all cases, little to no stress changes exceeding $\pm 0.1 \mathrm{MPa}$ are resolved on faults other than the West Napa fault.

\section{CONCLUSIONS}

Our results suggest the 2014 South Napa earthquake, in part, ruptured a previously unmapped strand of the West Napa fault 
with the majority of slip immediately adjacent to the city of Napa. The earthquake propagated northward from its hypocenter, rupturing shallow depths of $0-10.5 \mathrm{~km}$. Despite explicitly excluding field measurements of surface rupture from our inversions, the geodetic-based results are in strong agreement with these observations with respect to the locus and magnitude of surface rupture and the presence of rupture on a previously unmapped fault strands. Static CSC analysis shows that unruptured sections of the West Napa fault were positively stressed by the earthquake, with small stress changes (both positive and negative) resolved on neighboring faults, including the Green Valley and Contra Costa fault systems, Rodgers Creek fault, and Franklin fault. Systematic misfits to geodetic observations with postseismic intervals exceeding three days strongly suggest the presence of time-variable postseismic deformation that is not mapped into our fault-slip inversions and is in agreement with independent observations of afterslip on the West Napa fault (Brooks et al., 2014).

The South Napa earthquake provides an excellent opportunity to demonstrate the utility of geodetic observations in earthquake response efforts immediately following an event. InSAR and GPS made available immediately following the earthquake played a critical role in better constraining earthquake response products and helping to inform ensuing field surveys in the days following the South Napa earthquake. This specific example also demonstrates the quality, style, and extent of data sets needed to accurately map fault slip. For the South Napa earthquake, adding more observations to the original single interferogram and continuous GPS observations only marginally changed fault SDs (Fig. 3). Accordingly, spatially dense observations from a single interferogram or optical image-differencing approach may be sufficient to constrain the characteristics of a similar earthquake needed for products like ShakeMap and PAGER (fault location, dimensions, and depth).

Many additional observations were available to produce well-constrained SDs in the absence of geodesy for the South Napa earthquake, including field observations and a finite-fault slip model derived from local seismic recordings (http://earthquake .usgs.gov/earthquakes/eventpage/nc72282711\#scientific_finitefault; last accessed December 2014). However, most moderate and large earthquakes do not have such observations available, particularly in a time frame necessary for earthquake response, and earthquake response products have to rely on teleseismic source models that may contain substantial uncertainties with respect to event location, complexity, and spatial extent (Hayes, 2011; Barnhart, Hayes, Briggs, et al., 2014; Barnhart, Hayes, Samsonov, et al., 2014). Furthermore, teleseismic source models may not be suitably constrained for damaging events $M_{\mathrm{w}}<7$. Geodetic observations, and particularly remotely sensed geodetic observations (InSAR, electro-optical), thus provide two new advantages for global earthquake response. First, the spatial constraint (location and depth of centroid) afforded by geodetic observations helps to reduce uncertainties in event location and complexity of faulting that are not well constrained by teleseismic finite-fault models (Hayes, 2011; Barnhart, Hayes, Briggs, et al., 2014). Second, geodetic observations allow for accurate slip mapping of shallow, moderate-size earthquakes $\left(M_{\mathrm{w}}<7\right)$ in which teleseismic finite-fault models or field observations are not practical or immediately available. An analog to the South Napa earthquake, but in an environment with little to no regional observations, would be the $2003 M_{\mathrm{w}} 6.6$ Bam earthquake in Iran, which killed more than 26,000 people. Unfortunately, many geodetic observations are not available on the short time scales (hours to days versus minutes to hours) of teleseismic waveforms and source models (Hayes, 2011); thus, there is a trade-off between the accuracy afforded by geodetic observations and the time latency of acquiring them in regions devoid of continuous GPS networks.

After similar future earthquakes, accurate models like these that are generated soon after origin time may aid in characterizing time-dependent hazards through efforts such as operational earthquake forecasting (e.g., Jordan et al., 2014). Through improved geodetic observations and decreased time latency from forthcoming InSAR missions and refined analysis of high-rate GPS, the capabilities of earthquake response groups like the NEIC will further grow to expand the magnitude range of events that can be accurately characterized with a finite source. Although the modeling presented here is a simplification with respect to the large body of field observations that will be available to constrain the details of this earthquake, the collaboration between groups such as USGS, ARIA, and NRCAN enabled rapid and accurate source characterization of a moderate yet damaging earthquake. $\mathbf{Z}$

\section{ACKNOWLEDGMENTS}

The authors thank Gavin Hayes and three anonymous reviewers for helpful reviews that improved the quality of this manuscript. This project, in part, was carried out using CSK products ( ${ }^{\odot}$ Italian Space Agency [ASI]), delivered under the ASI license provided under the Caltech/JPL-ASI/CIDOT CaliMap project. Original RADARSAT-2 data is copyrighted by MacDonald, Dettwiler and Associates Ltd. (MDA; ${ }^{\circ} 2014$ ). Continuous Global Positioning System data used in this study were recorded by instruments of the Plate Boundary Observatory (PBO, http://pbo.unavco.org/; last accessed December 2014) and the Bay Area Regional Deformation (BARD) network (http:// seismo.berkeley.edu/bard/; last accessed December 2014). The PBO is operated by UNAVCO for EarthScope (www.earthscope. org; last accessed December 2014) and supported by the National Science Foundation (Numbers EAR-0350028 and EAR0732947). Part of this research was supported by the National Aeronautics and Space Administration Earth Surface and Interior focus area and Applied Sciences Program and performed at the Jet Propulsion Laboratory, California Institute of Technology. W. D. B. was supported by a U.S. Geological Survey (USGS) Mendenhall Postdoctoral fellowship at the USGS Geological Hazards Center. J. R. M., J. L. S., and B. A. B. were supported by the USGS Earthquake Science Center. This is Natural Resources Canada Earth Science Sector Contribution Number 20140320. Several figures were generated using the Generic Mapping Tool (Wessel and Smith, 1998). Any use of trade, 
product, or firm names is for descriptive purposes only and does not imply endorsement by the U.S. Government.

\section{REFERENCES}

Barnhart, W. D., and R. B. Lohman (2010). Automated fault model discretization for inversions for coseismic slip distributions, J. Geophys. Res. 115, no. B10, doi: 10.1029/2010JB007545.

Barnhart, W. D., G. P. Hayes, R. W. Briggs, R. D. Gold, and R. Bilham (2014). Ball-and-socket tectonic rotation during the 2013 Balochistan earthquake, Earth Planet. Sci. Lett. 403, 210-216, doi: 10.1016/j.epsl.2014.07.001.

Barnhart, W. D., G. P. Hayes, S. V. Samsonov, E. J. Fielding, and L. E. Seidman (2014). Breaking the oceanic lithosphere of a subducting slab: The 2013 Khash, Iran earthquake, Geophys. Res. Lett. 41, no. 1, doi: 10.1002/2013GL058096.

Barnhart, W. D., R. B. Lohman, and R. J. Mellors (2013). Active accommodation of plate convergence in southern Iran: Earthquake locations, triggered aseismic slip, and regional strain rates, J. Geophys. Res. 118, no. 10, 5699-5711, doi: 10.1002/jgrb.50380.

Barnhart, W. D., M. J. Willis, R. B. Lohman, and A. K. Melkonian (2011). InSAR and optical constraints on fault slip during the 2010-2011 New Zealand earthquake sequence, Seismol. Res. Lett. 82, no. 6, 815-823, doi: $10.1785 /$ gssrl.82.6.815.

Bertiger, W., S. D. Desai, B. Haines, N. Harvey, A. W. Moore, S. Owen, and J. P. Weiss (2010). Single receiver phase ambiguity resolution with GPS data, J. Geodes. 84, no. 5, 327-337, doi: 10.1007/s00190010-0371-9.

Brooks, B. A., K. Hudnut, C. L. Glennie, and T. Ericksen (2014). Nearfield deformation associated with the M 6.0 South Napa earthquake surface rupture, in American Geophysical Union Fall Meeting, abstract S33F-4900, San Francisco, California, 15-19 December 2014.

Chen, C. W., and H. A. Zebker (2001). Two-dimensional phase unwrapping with use of statistical models for cost functions in nonlinear optimization, J. Opt. Soc. Am. Optic. Image Sci. Vis. 18, no. 2, 338-351.

d'Alessio, M. A., I. A. Johanson, R. Bürgmann, D. A. Schmidt, and M. H. Murray (2005). Slicing up the San Francisco Bay area: Block kinematics and fault slip rates from GPS-derived surface velocities, J. Geophys. Res. 110, no. B6, B06403, doi: 10.1029/2004JB003496.

Devlin, S., B. L. Isacks, M. E. Pritchard, W. D. Barnhart, and R. B. Lohman (2012). Depths and focal mechanisms of crustal earthquakes in the central Andes determined from teleseismic waveform analysis and InSAR, Tectonics 31, no. 2, doi: 10.1029/2011TC002914.

Dong, D., P. Fang, Y. Bock, F. Webb, L. Prawirodirdjo, S. Kedar, and P. Jamason (2006). Spatiotemporal filtering using principal component analysis and Karhunen-Loeve expansion approaches for regional GPS network analysis, J. Geophys. Res. 111, no. B3, B03405, doi: 10.1029/2005JB003806.

Elliott, J. R., R. J. Walters, P. C. England, J. A. Jackson, Z. Li, and B. Parsons (2010). Extension on the Tibetan plateau: Recent normal faulting measured by InSAR and body wave seismology, Geophys. J. Int. 183, no. 2, 503-535, doi: 10.1111/j.1365-246X.2010.04754.x.

Evans, E. L., J. P. Loveless, and B. J. Meade (2012). Geodetic constraints on San Francisco Bay area fault slip rates and potential seismogenic asperities on the partially creeping Hayward fault, J. Geophys. Res. 117, no. B3, B03410, doi: 10.1029/2011JB008398.

Farr, T. G., P. A. Rosen, E. Caro, R. Crippen, R. Duren, S. Hensley, M. Kobrick, M. Paller, E. Rodriguez, L. Roth, D. Seal, S. Shaffer, J. Shimada, J. Umland, M. Werner, M. Oskin, D. Burbank, and D. Alsdorf (2007). The Shuttle Radar Topography Mission, Rev. Geophys. 45, no. 2, doi: 10.1029/2005RG000183.

Field, E. H., R. J. Arrowsmith, G. P. Biasi, P. Bird, T. E. Dawson, K. R. Felzer, D. D. Jackson, K. M. Johnson, T. H. Jordan, C. Madden, A. J. Michael, K. R. Milner, M. T. Page, T. Parsons, P. M. Powers, B. E. Shaw, W. R. Thatcher, R. J. Weldon II, and Y. Zeng (2014). Uniform California earthquake rupture forecast, version 3 (UCERF3) -
The time-independent model, Bull. Seismol. Soc. Am. 104, no. 3, 1122-1180, doi: 10.1785/0120130164.

Freed, A. M. (2005). Earthquake triggering by static, dynamic, and postseismic stress transfer, Annu. Rev. Earth Planet. Sci. 33, no. 1, 335367, doi: 10.1146/annurev.earth.33.092203.122505.

Funning, G. J., R. Bürgmann, A. Ferretti, F. Novali, and A. Fumagalli (2007). Creep on the Rodgers Creek fault, northern San Francisco Bay area from a 10 year PS-InSAR dataset, Geophys. Res. Lett. 34, no. 19, L19306, doi: 10.1029/2007GL030836.

Goldstein, R. M., H. A. Zebker, and C. L. Werner (1988). Satellite radar interferometry: Two-dimensional phase unwrapping, Radio Sci. 23, no. 4, 713-720, doi: 10.1029/RS023i004p00713.

Harris, R. A. (1998). Introduction to special section: Stress triggers, stress shadows, and implications for seismic hazard, J. Geophys. Res. 103, no. B10, 24347-24358, doi: 10.1029/98JB01576.

Hayes, G. P. (2011). Rapid source characterization of the $2011 M_{\mathrm{w}} 9.0$ Off the Pacific Coast of Tohoku earthquake, Earth Planets Space 63, 529-534, doi: 10.5047/eps.2011.05.012.

Hayes, G. P., M. W. Herman, W. D. Barnhart, K. P. Furlong, S. Riquelme, H. M. Benz, E. Bergman, S. Barrientos, P. S. Earle, and S. Samsonov (2014). Continuing megathrust earthquake potential in Chile after the 2014 Iquique earthquake, Nature 512, no. 7514, 295-298, doi: 10.1038 /nature13677.

Jordan, T. H., W. Marzocchi, A. J. Michael, and M. C. Gerstenberger (2014). Operational earthquake forecasting can enhance earthquake preparedness, Seismol. Res. Lett. 85, no. 5, 955-959, doi: 10.1785/ 0220140143.

Kilb, D., J. Gomberg, and P. Bodin (2000). Triggering of earthquake aftershocks by dynamic stresses, Nature 408, no. 6812, 570-574, doi: $10.1038 / 35046046$.

Langbein, J. (2004). Noise in two-color electronic distance meter measurements revisited, J. Geophys. Res. 109, no. B4, B04406, doi: 10.1029/2003JB002819.

Lohman, R. B., and W. D. Barnhart (2010). Evaluation of earthquake triggering during the 2005-2008 earthquake sequence on Qeshm Island, Iran, J. Geophys. Res. 115, no. 12413, doi: 10.1029/2010JB007710.

Lohman, R. B., and M. Simons (2005). Some thoughts on the use of InSAR data to constrain models of surface deformation: Noise structure and data downsampling, Geochem. Geophys. Geosystems 6, no. 1, doi: 10.1029/2004GC000841.

Murray, J. R., S. E. Minson, and J. L. Svarc (2014). Slip rates and spatially variable creep on faults of the northern San Andreas system inferred through Bayesian inversion of Global Positioning System data, J. Geophys. Res. 119, no. 7, doi: 10.1002/2014JB010966.

Okada, Y. (1992). Internal deformation due to shear and tensile faults in a half-space, Bull. Seismol. Soc. Am. 82, no. 2, 1018-1040.

Rodgers, A., N. A. Petersson, S. Nilsson, B. Sjögreen, and K. McCandless (2008). Broadband waveform modeling of moderate earthquakes in the San Francisco Bay area and preliminary assessment of the USGS 3D seismic velocity model, Bull. Seismol. Soc. Am. 98, no. 2, 969988, doi: 10.1785/0120060407.

Sambridge, M. (1999). Geophysical inversion with a neighbourhood algorithm-I. Searching a parameter space, Geophys. J. Int. 138, no. 2, 479-494, doi: 10.1046/j.1365-246X.1999.00876.x.

Savage, J. C., J. L. Svarc, and W. H. Prescott (1999). Geodetic estimates of fault slip rates in the San Francisco Bay area, J. Geophys. Res. 104, no. B3, 4995-5002, doi: 10.1029/1998JB900108.

Stein, R. S. (1999). The role of stress transfer in earthquake occurrence, Nature 402, no. 6762, 605-609, doi: 10.1038/45144.

Wdowinski, S., Y. Bock, J. Zhang, P. Fang, and J. Genrich (1997). Southern California permanent GPS geodetic array: Spatial filtering of daily positions for estimating coseismic and postseismic displacements induced by the 1992 Landers earthquake, J. Geophys. Res. 102, no. B8, 18057-18070, doi: 10.1029/97JB01378.

Wegmuller, U., and C. Werner (1997). GAMMA SAR processor and interferometry software, in 3rd ERS Symposium on Space at the Service of our Environment, Florence, Italy, 17-21 March 1997. 
Wesling, J. R., and K. L. Hanson (2008). Mapping of the West Napa fault zone for input into the California Quaternary fault database, USGS Final Technical Rept. No. O5HQAG0002.

Wessel, P., and W. H. F. Smith (1998). New, improved version of Generic Mapping Tools released, Eos Trans. $A G U 79$, no. 47, 579-579, doi: 10.1029/98EO00426.

Zebker, H., S. Hensley, P. Shanker, and C. Wortham (2010). Geodetically accurate InSAR data processor, IEEE Trans. Geosci. Remote Sens. 48, no. 12, 4309-4321, doi: 10.1109/TGRS.2010.2051333.

Zumberge, J. F., M. B. Heflin, D. C. Jefferson, M. M. Watkins, and F. H. Webb (1997). Precise point positioning for the efficient and robust analysis of GPS data from large networks, J. Geophys. Res. 102, no. B3, 5005-5017, doi: 10.1029/96JB03860.

W. D. Barnhart

Department of Earth and Environmental Sciences The University of Iowa 121 Trowbridge Hall

Iowa City, Iowa 52242 U.S.A. william-barnhart-1@uiowa.edu

J. R. Murray
J. L. Svarc
B. A. Brooks
U.S. Geological Survey Earthquake Science Center
345 Middlefield Road
Menlo Park, California 94025 U.S.A.

S.-H. Yun

E. J. Fielding

Jet Propulsion Laboratory California Institute of Technology M/S 300-233, 4800 Oak Grove Drive Pasadena, California 91109 U.S.A.

\author{
S. V. Samsonov \\ Natural Resources Canada \\ 590 Rochester Street \\ Ottawa, Ontario K1A OE4, Canada
}

\author{
P. Milillo ${ }^{2}$ \\ Seismological Laboratory \\ California Institute of Technology \\ 1200 E. California Boulevard, MS 252-21 \\ Pasadena, California 91125 U.S.A.
}

\footnotetext{
${ }^{1}$ Also at U.S. Geological Survey Geological Hazards Center, 1711 Illinois Street, Golden, Colorado 80401 U.S.A.

2 Also at School of Engineering, Universita' degli Studi della Basilicata, Potenza, Italy.
} 